to every chemist, student, and expert alike, for it should go far to dispel that somewhat doubtful confidence which the author quite rightly complains is still felt by the pure chemist as regards this important and fascinating branch of science.

$$
\text { E. C. C. Baly. }
$$

\section{THE CONSTITUTION OF THE SILICATES.}

Die Silicate in chemischer und technischer Beziehung: unter Zugrundelegung der seitens der philosophischen Fakultät der Universität Göttingen preisgekrönten Hexitpentit-Theorie nebst Umwandlung derselben in eine allgemeine stereochemische Theorie. By Dr. W. Asch and Dr. D. Asch. Pp. $x v+409$. (Berlin: Julius Springer, r9I.) Price 16 marks.

$7 \mathrm{HE}$ present work, which is an expansion of an essay originally submitted for a prize offered by the philosophical faculty of Göttingen, is a bold and original attempt to grapple with the difficult problem of the chemistry of the silicates and related compounds. The authors have sought to give a structural explanation of the behaviour of such compounds consistent with the doctrine of valency. 'The "Hexite-Pentite" hypothesis, which forms the basis of the work, assumes that silicates and alumino-silicates are not, in general, derived from the simpler hydroxides, such as $\mathrm{Si}(\mathrm{OH})_{4}$ and $\mathrm{Al}(\mathrm{OH})_{3}$, but from compounds formed by the condensation of six such molecules, with elimination of water, to form a closed ring. Less frequently, five-membered rings may be produced, and complex molecules are built up by the union, according to certain definite principles, of two or more such "hexite" or "pentite" groups. By the replacement of hydroxylic hydrogen by metals, of hydroxyl by fluorine, \&c., formulæ are constructed which are capable of expressing with remarkable completeness the properties and reactions of many silicates and aluminosilicates.

The formulæ, especially in the contracted notation chiefly employed in the text, strongly recall the Kekule theory of aromatic carbon compounds, but the analogy is not a real one, as the linking is never from silicon to silicon or aluminium, but always through an intervening oxygen atom. Praise is due to the authors for the ingenuity with which the hypothesis is applied, and for the labour expended in recalculating the enormous number of analyses given, and expressing them in terms of the new structural theory. A certain arbitrariness in the choice of many of the formulæ is unavoidable, in the absence of experimental investigations specially designed to test the points in question.

The most serious defect of the work is its disregard of physical considerations, owing to the NO. 22 I 8, VOL. 89] exclusively chemical viewpoint adopted. This onesidedness is well seen in the lengthy and detailed treatment of Portland cement and blast-furnace slag. Definite hexite-pentite formulæ are assigned to a great variety of these artificial products on the evidence of ultimate analyses only, and the microscopical proof that such materials are heterogeneous is brushed aside in a single sentence. Thermal analysis, by means of which such great advances are being made, including the brilliant work of the Geophysical Laboratory in Washington, is not considered, and the names of Day, Shepherd, and their collaborators do not even appear in the bibliography, although this includes some ${ }_{5} 500$ references. Again, the great additions made in recent years to our knowledge of colloids and of the part played by them in the chemistry of silicates are passed over in silence or with a brief allusion, in spite of the intimate bearing of such work on the weathering of felspars, the setting of cements, the hydration of zcolites, and similar questions, all of which are discussed from a purely structural point of view. Even to glasses and porcelain definite structural formulæ are assigned.

By replacing silicon and aluminium atoms by other elements, and by introducing stereochemical considerations, the hypothesis is extended to complex salts, metal-ammonia compounds, and salts with water of crystallisation. Some shorter chapters are devoted to further and more hazardous speculations, the hexite-pentite arrangement being applied to aliphatic organic compounds, and even to the structure of the atom and the explanation of radioactivity. These extravagances, however, do not detract from the value of the main thesis, which certainly deserves the attention of inorganic chemists and mineralogists, as possibly affording assistance in the further study of a complex and difficult subject. C. H. Descr.

\section{BRITISH VEGETATION}

Types of British Vegetation. By members of the Central Committee for the Survey and Study of British Vegetation. Edited by A. G. Tansley. Pp. $x x+416+36$ plates. (Cambridge: University Press, I9II.) Price 6s. net.

7 HE great impetus that has been given during recent years to the study of the British flora is largely owing to the development of that branch of botany known as ecology. This subject-the study of plants in connection with their habitathas raised many questions, and amongst them that of plant-communities has received foremost attention, and has been zealously investigated. The committee which was formed in 1904 to 